\title{
Etnomatemática e resolução de problemas como proposta metodológica para o Ensino Fundamental
}

\author{
Ethnomathematics and Problem Solving as a methodological proposal to the \\ Elementary Education
}

\author{
Renata Cristina Geromel Meneghetti ${ }^{1}$ \\ Manoel de Souza Lamim Netto ${ }^{2}$ \\ Edna Maura Zuffi ${ }^{3}$
}

\begin{abstract}
Resumo
Este trabalho visa contribuir com propostas metodológicas alternativas para o processo de ensino e aprendizagem de Matemática no contexto escolar da Educação Básica e tem por objetivo investigar a possibilidade de implementação de uma proposta de ensino de Matemática baseada na metodologia de ensinoaprendizagem-avaliação através da resolução de problemas, agregada aos princípios da Etnomatemática. A pesquisa seguiu uma abordagem qualitativa, caracterizada como um estudo de caso referente à aplicação da metodologia mencionada junto a alunos do oitavo ano do Ensino Fundamental, evidenciando também alguns elementos da pesquisa-ação. As situações-problema foram contextualizadas à realidade sociocultural dos alunos, a partir do tema gerador "água", escolhido e definido com os participantes. Os dados foram coletados e analisados através de questionários, entrevistas, registros audiovisuais e anotações em diário de campo. As análises apontaram que tal aplicação significou um avanço, tanto nos conhecimentos de Matemática quanto naqueles relativos à temática trabalhada e que, para tal, foi de fundamental importância a integração dos saberes matemáticos oriundos do contexto escolar com aqueles existentes na comunidade da qual os educandos faziam parte.
\end{abstract}

Palavras-chave: Educação Básica, Etnomatemática, Metodologias Alternativas, Resolução de Problemas.

\begin{abstract}
This work aims to contribute with alternative methodological proposals for the teaching and learning process of Mathematics in school context of Basic Education, and aims to investigate the possibility of implementing a proposal for teaching Mathematics based on the teaching-learning-assessment methodology through problem
\end{abstract}

\section{Submetido em: 25/05/2020 - Aceito em: 19/07/2021 - Publicado em: 20/10/2021}

${ }^{1}$ Doutora em Educação Matemática Universidade Estadual Paulista Júlio de Mesquita Filho (UNESP/Rio Claro/Brasil). Professora Associada do Instituto de Ciências Matemáticas e de Computação (ICMC) da Universidade de São Paulo (USP), São Carlos. Professora Colaboradora junto ao Programa de Pós-graduação em Educação para Ciência, UNESP (FC), Bauru, Brasil. Email: rcgm@icmc.usp.br. ORCID: http://orcid.org/0000-0002-8482-4001

2 Mestrando em Educação para Ciência, UNESP (FC), Bauru. Licenciado em Matemática pelo Instituto de Ciências Matemáticas e de Computação da USP, Brasil. Primeiro Tenente Aluno (1 Ten Al) do Curso de Formação de Oficiais (CFO 2021) da Escola de Formação Complementar do Exército e Colégio Militar de Salvador, Brasil. Email: manoel.lamim.netto@gmail.com. ORCID: http://orcid.org/0000-0002-5873-3376

3 Doutora em Educação pela Universidade de São Paulo. Professora do Departamento de Matemática, do Instituto de Ciências Matemáticas e de Computação da USP, Brasil. Email: edna@icmc.usp.br. ORCID: http://orcid.org/0000-0003-3353-7851 
solving, added to the principles of Ethnomathematics. The research followed a qualitative approach, characterized as a case study referring to the application of the previous methodology with students of the eighth grade of Elementary School, also showing some elements of action-research. The problem situations were contextualized to the students' sociocultural reality, based on the generator theme "water", chosen and defined with the participants. Data were collected and analyzed through questionnaires, interviews, audiovisual records and notes in a field diary. The analysis pointed out that such an application meant an advance, both in the knowledge of Mathematics and in those related to the theme worked on and that, for this, it was of fundamental importance the integration of mathematical knowledge from the school context with those existing in the community from which the students were part of.

Keywords: Basic Education, Ethnomathematics, Alternative Methodologies, Problem Solving.

\section{Introdução}

No âmbito da Educação Matemática, estudos apontam dificuldades nos processos de ensino e aprendizagem, principalmente relacionadas ao emprego demasiado e exclusivo de abordagens tradicionais e a um ensino desarticulado das práticas cotidianas dos educandos (Fiorentini \& Miorim, 1990). Outrossim, Teixeira (2004) destaca que a Matemática é uma disciplina de cunho procedimental, de conceitos abstratos, dedutivos e de natureza não empírica. Consequentemente, tem sido relatada pelos professores como extremamente difícil, a proposição de ações alternativas de ensino de Matemática nos contextos escolares.

No Brasil, os Parâmetros Curriculares Nacionais (PCN) expressaram as contribuições de pesquisas da área da Educação Matemática que começaram a penetrar nas escolas e nos cursos de formação de professores, no contexto das reformas educacionais da década de 90 . As novas concepções salientaram a importância da Matemática enquanto fomentadora da criatividade, da investigação e de habilidades de resolução de problemas (Brasil, 1998). Tais perspectivas também destacaram o papel relevante dos aspectos culturais e sociais dos conteúdos dessa disciplina, numa tentativa de agregar dimensões éticas ao currículo tradicional, reformulando, assim, os objetivos de seu ensino (Pires, 2008).

Destacamos a necessidade de reconceituar o currículo matemático escolar e gerar maiores significados para os educandos nas salas de aula. Nesse sentido, este trabalho faz parte de uma pesquisa de âmbito maior e tem como objetivo investigar a implementação de uma proposta alternativa para o processo de ensino e aprendizagem de Matemática, no contexto escolar da Educação Básica, que se baseou na metodologia de ensino-aprendizagemavaliação através da resolução de problemas (Onuchic, Allevato, Noguti \& Justulin, 2014), associada aos princípios da Etnomatemática (D’Ambrosio, 1990), em sua dimensão educacional.

Para tal, orientamo-nos pelos seguintes questionamentos: (1) É possível implementar com êxito, e mais continuamente, uma metodologia alternativa de ensino, baseada em aspectos da Etnomatemática e através da Resolução de Problemas, nas condições atuais oferecidas pela escola pública brasileira, no Ensino Fundamental? (2) Quais as dificuldades encontradas nesta implementação? (3) O que o modelo proposto nesta metodologia pode significar em termos da aprendizagem matemática dos alunos participantes?

Nesta direção, no presente artigo abordaremos um recorte da aplicação desta proposta 
junto a alunos do oitavo ano do Ensino Fundamental de uma escola da rede pública estadual paulista, por meio do projeto de iniciação científica do segundo autor, sob a orientação da primeira e a partir de reflexões conjuntas com a terceira, no esforço de conectar a Matemática formal ao contexto sociocultural da comunidade escolar, à luz dos seguintes referenciais teóricos.

\section{Pressupostos teóricos}

Adotamos nesta pesquisa, como referenciais teórico-metodológicos a Etnomatemática e a metodologia de ensino-aprendizagem-avaliação através da Resolução de Problemas. A conjugação dessas perspectivas ocorreu na medida que valorizamos os aspectos culturais da comunidade escolar e desenvolvemos os conteúdos matemáticos a partir de situaçõesproblema advindas deste espaço cultural. Desse modo, a partir da realidade e da demanda escolar, elaboramos e executamos atividades de intervenção junto ao professor e à turma participante que foram agregadas a uma determinada temática, no esforço de que tais situações-problema fossem capazes de desencadear o processo de ensino e aprendizagem.

\section{A Resolução de Problemas no ensino de Matemática}

Um problema pode ser compreendido como "qualquer situação que leve o aluno a pensar e que lhe seja desafiadora e não trivial" (Onuchic, 1999, p. 215). Desse modo, é caracterizado por ser difícil para aquele que se propõe a resolvê-lo, na medida que este não possui métodos ou ferramentas para resolvê-lo de antemão. Essa definição vai ao encontro da nossa proposta de iniciar o trabalho em sala de aula a partir de uma situação-problema.

A esse propósito, Onuchic e Allevato (2005) destacam três formas de trabalhar a resolução de problemas na sala de aula: o ensino sobre, para, e através da resolução de problemas. Quanto à primeira, é notória a influência na literatura da obra "A arte de resolver problemas”, de Polya (1978), na qual são propostas estratégias, passo a passo, aplicáveis à resolução de quaisquer problemas. Já o ensino para a Resolução de Problemas consiste em fornecer algum aporte teórico ao aluno que recebe os conhecimentos matemáticos transmitidos pelo professor para poder aplicá-los. Desse modo, focaliza-se o aspecto utilitário da Matemática, abordando-se primeiramente os conceitos formais para depois empregá-los na resolução dos problemas.

Adotaremos, nesta proposta, a terceira concepção, do ensino e aprendizagem através da Resolução de Problemas, na qual o saber a ser ensinado inicia-se por meio de um problema. Sob esta perspectiva, "o problema é o ponto de partida para a construção de novos conceitos; os alunos sendo co-construtores de seu próprio conhecimento e, os professores, os responsáveis por conduzir esse processo" (Onuchic \& Allevato, 2005, p. 80).

Ao ensinar através da Resolução de Problemas, acreditamos ter a oportunidade de propiciar um diálogo mais intenso entre professor-aluno e aluno-aluno, permitindo uma maior aproximação entre eles na busca de soluções para os problemas (Onuchic, 1999; Mandarino, 2002) e, assim, promover um ambiente rico para aprender Matemática, além de favorecer a 
construção de novos conceitos pelos próprios alunos, de modo mais significativo (Onuchic \& Allevato, 2005).

Onuchic et al. (2014) propuseram a expressão "ensino-aprendizagem-avaliação" para evidenciar a importância de as práticas avaliativas ocorrerem junto com a resolução dos problemas. Também organizaram a metodologia em dez etapas: (1) Proposição do problema; (2) Leitura individual; (3) Leitura em conjunto; (4) Resolução do problema; (5) Observação e incentivo; (6) Registro das resoluções na lousa; (7) Plenária; (8) Busca de consenso; (9) Formalização do conteúdo e (10) Proposição de novos problemas.

Esse roteiro de atividades é sugerido a fim de orientar o educador e educandos durante o desenvolvimento da metodologia. A proposição de uma situação-problema (etapa 1) deve visar à construção de um novo conteúdo e pode estar inserida no contexto de algum projeto da escola. Para esta pesquisa, acrescentamos que ela deveria relacionar-se ao contexto sociocultural da comunidade dos participantes, conectando, assim, dois pressupostos teóricos, como veremos mais adiante. Esta última abordagem insere-se na perspectiva da Etnomatemática, uma vez que os alunos envolvidos elegeram como aspecto social relevante para sua comunidade local, verificar se havia tratamentos adequados para a água consumida na cidade e, também, para o esgoto ali gerado. Ou seja, a temática levanta faz parte do contexto sociocultural dos alunos e era de interesse deles investigar sobre isso com mais profundidade.

As cinco primeiras etapas acima expostas dizem respeito à resolução da situaçãoproblema propriamente dita, nas quais o professor age mediando a construção de possíveis soluções pelos alunos. Nas demais, essas soluções são apresentadas e discutidas conjuntamente com a colaboração do professor para se chegar a um consenso. Este, então, assume o papel de promover a formalização e síntese dos conceitos, podendo valer-se de outros instrumentos avaliativos após essas etapas.

\section{Etnomatemática}

Este trabalho também está alinhado com os pressupostos teóricos do Programa Etnomatemática, o qual propõe o estudo da criação e transmissão dos conhecimentos matemáticos em seus aspectos culturais, em suas diversas formas e locais do mundo. A Etnomatemática compreende os procedimentos, as ideias e as práticas matemáticas enquanto produtos sociais, atrelados aos contextos culturais de diversos povos que empregam a Matemática para explicar, entender, compreender e modelar os fenômenos que ocorrem em suas vidas diárias (D’Ambrosio, 1990). No cenário escolar, nesta perspectiva, entende-se que o processo educativo deve estar atrelado ao contexto sociocultural dos alunos.

Nesse sentido, os princípios do programa Etnomatemática podem ser utilizados numa dimensão educacional em processos de ensino e aprendizagem de matemática em sala de aula, contribuindo para se repensar a Matemática enquanto disciplina escolar, o que se dá a partir da inserção de componentes socioculturais nesse currículo. Tais ações pedagógicas salientam a importância de ensinar e aprender Matemática de maneira mais transdisciplinar e 
transcultural, atrelada a diversos contextos e situações, em um processo conscientizador das diferenças culturais existentes na comunidade escolar (Wanderer \& Knijnik, 2008; Rosa et al., 2016).

Desse modo, defendemos que é imprescindível que educadores discutam a existência de outras formas de fazer e saber a Matemática. Torna-se indispensável à integração entre o conteúdo matemático curricular e a comunidade na qual estão inseridos os educandos, no sentido de valorizar contextos locais, nos quais os alunos estão inseridos, para além do ambiente escolar. Para tal, a promoção de ambientes de aprendizagem e de sequências pedagógicas que favoreçam o emprego de estratégias de investigação e de resolução de problemas é uma oportunidade para reconceituar o currículo nesta área do saber.

Tal reconceituação, embora necessária, não implica ignorar a Matemática acadêmica formal, mas aprimorá-la e humanizá-la, em um movimento de valorização dos aspectos históricos e culturais desse conhecimento. (D’Ambrosio, 1990). Nesse sentido, reconhecemos a necessidade de atribuir sentido social ao conhecimento matemático que desenvolvemos em sala de aula.

Um ensino pautado na Etnomatemática não deve incorrer por meio da utilização, repetição e reprodução pelo educando de um conhecimento que está no livro didático, mas sim num processo dinâmico, em resposta a problemas/desafios sociais e/ou culturais cotidianos. Assim, é importante que o educador possa propor situações de ensino e aprendizagem, os quais o educando caminha na direção de resolver e explicar situações gerais do seu ambiente cultural (D’AMBROSIO, 2008).

E, no caso aqui analisado, a escolha dos estudos sobre a água foi feita pelos alunos, entre algumas sugestões dadas pelo professor regente da turma investigada, por considerarem dos mais relevantes para a qualidade de vida local, os conhecimentos sobre de onde provinha essa água, sobre como era feito o tratamento da mesma e se os esgotos gerados nessa comunidade eram tratados, ou se estavam contribuindo para a poluição de rios do entorno, etc.

\section{Aspectos metodológicos desta investigação}

Acreditamos ser importante que o trabalho com a Resolução de Problemas em sala de aula leve em consideração o contexto sociocultural do educando e da comunidade na qual a escola está inserida, de modo que as situações-problema ganhem maior significado dentro desse contexto. Nesse sentido, a comunidade escolar possui todos os elementos necessários para o desenvolvimento de um currículo matemático mais significativo para o educando, porque as diferenças culturais coexistem nesse espaço (Rosa \& Orey, 2017).

Nesse sentido, Rosa e Orey (2017) destacam que a adoção de princípios teóricos da Etnomatemática nas atividades de Resolução de Problemas pode auxiliar professores e alunos nos processos de ensino e aprendizagem de Matemática em sala de aula, a fim de articular os conhecimentos advindos de situações específicas com aqueles matematicamente 
institucionalizados.

Compreendemos, assim como Monteiro (2004), que a Etnomatemática ainda não se constitui enquanto método de ensino de Matemática e que "apesar de suas contribuições para o contexto escolar, devido a seu caráter mais filosófico e pela incipiência de debates sobre o tema, a implementação de propostas educacionais no ensino básico são escassas" (Gonçalves, Bandeira \& Araújo Júnior, 2013, p. 1). Daí a importância de estudos e investigações nesta direção, tal como o que apresentamos neste artigo.

Neste trabalho objetivamos integrar os pressupostos teóricos da Etnomatemática e os metodológicos relativos à Resolução de Problemas, a partir da adoção dessas duas perspectivas simultaneamente. Acreditamos que o contexto sociocultural da comunidade escolar é capaz de fornecer excelentes situações-problema, a partir das quais podemos implementar a metodologia de ensino através da Resolução de Problemas, atrelada ao princípios da Etnomatemática. É importante destacar que a literatura da área já reporta algumas pesquisas que buscaram integrar essas duas perspectivas (Pereira \& Bandeira, 2016; Gonçalves, Bandeira \& Araújo Júnior, 2013).

Tendo em vista os aportes teóricos expostos e a discussão apresentada, esta pesquisa justifica-se pela necessidade de gerar maiores significados nas salas de aula de Matemática, no contexto escolar da Educação Básica, ao se aproximarem duas abordagens como uma proposta unificada e organizada pedagogicamente para este contexto.

\section{Metodologia da Pesquisa}

Adotamos uma abordagem qualitativa de investigação, com características de estudo de caso e da pesquisa-ação. O primeiro caracteriza-se pelo olhar do pesquisador para algum elemento bem definido de investigação, quer seja um indivíduo ou grupo de sujeitos, uma instituição, um programa ou um evento (Alves-Mazzotti, 2006). Além disso, o estudo de caso permite compreender o mundo do ponto de vista dos participantes (Fonseca, 2002). Esta investigação também se caracteriza como do tipo pesquisa-ação, na medida em que modifica o ambiente investigado e busca reforçar a relação entre pesquisador e sujeitos participantes (Thiollent, 2000). Neste trabalho, o pesquisador atuou como professor temporário da turma, durante a aplicação das atividades, ou seja, o professor oficial dos alunos cedeu espaço para a atuação do pesquisador no papel de professor, com as ações propostas tendo sido executadas sempre em concordância com o professor regente e sob a tutoria do mesmo. Porém, esse professor, embora tenha atuado como importante colaborador no fornecimento de dados sobre a turma e sobre os conteúdos matemáticos que vinham sendo trabalhados, não se envolveu com o desenvolvimento e execução da sequência didática aqui analisada e, portanto, consideramos que não se constituiu propriamente como sujeito desta investigação.

Os sujeitos de pesquisa eram alunos do oitavo ano do Ensino Fundamental de uma escola pública do estado de São Paulo. A turma participante tinha cerca de 23 alunos matriculados, em uma faixa etária de 13 anos de idade, aproximadamente. Os dados foram coletados e analisados através de questionários, aplicados junto aos alunos, entrevistas com o 
professor regente, para detalhamento das características da turma, dos recursos didáticos que eram utilizados regularmente e dos conteúdos que vinham sendo desenvolvidos, além de registros audiovisuais e anotações em diário de campo.

Para o desenvolvimento e aplicação da intervenção, seguimos o seguinte percurso metodológico: (1) a partir de uma entrevista realizada com o professor da turma, levantamos os principais assuntos do currículo matemático nos quais havia dificuldades para seu ensino e aprendizagem e para a obtenção de resultados positivos de aprendizagem; (2) aplicamos um primeiro questionário junto aos alunos objetivando levantar informações sobre suas concepções e dificuldades quanto à Matemática; (3) apresentamos, em colaboração com o professor participante e em consonância com as respostas fornecidas no primeiro questionário, uma proposta de atividades alternativas à luz das teorias postas, objetivando uma maior participação e geração de significados nas aulas de Matemática. Neste momento definimos um tema gerador: "água", detalhado mais adiante; (4) aplicamos o segundo questionário com os alunos, visando identificar os conhecimentos prévios acerca do tema e dos assuntos de Geometria, escolhido como conteúdo a ser desenvolvido com a proposta metodológica; (5) aplicamos as atividades planejadas, que compreenderam as etapas de investigação exploratória e Resolução de Problemas; (6) aplicamos um terceiro e quarto questionários junto aos alunos, a fim de identificar o progresso dos educandos com relação aos conhecimentos de Matemática construídos.

De acordo com Freire (1987), um tema gerador deve ser gerado a partir da problematização da prática de vida dos educandos e deverá ser o ponto inicial do processo educativo.

No caso focado neste artigo, o tema gerador, trata-se de uma problemática, ou preocupação, eleita pelos alunos participantes da pesquisa, como socialmente relevante para ser desenvolvida, a partir da qual a sequência didática seria proposta, com vistas a gerar novos conhecimentos matemáticos e sociais, articulando-os na contextualização das principais atividades de ensino propostas nesta sequência, relativamente a aspectos da realidade cultural em que os alunos estavam inseridos. Como já citado anteriormente, a questão da origem, tratamento e descarte da água consumida localmente foi considerada, pelos alunos, a mais relevante a ser estudada.

\section{Aplicação e resultados}

\section{Diagnóstico inicial e definição de um tema}

Realizamos um diagnóstico inicial a partir das quatro primeiras etapas descritas anteriormente. Inicialmente, a entrevista com o professor destacou a sua preocupação quanto ao aprendizado de Geometria, devido, sobretudo, às dificuldades que os alunos demonstravam neste tópico em particular. Somado a isso, a definição de um tema para as atividades levou em consideração as respostas dadas ao primeiro questionário realizado com a turma participante, o qual teve como objetivo compreender a percepção dos educandos quanto à Matemática e em quais situações ela está presente em suas vidas. 
A análise deste questionário apontou para sugestões dos alunos bastante diversificadas e pouco conclusivas, das quais destacamos: a inclusão de materiais manipulativos, a elaboração de maquetes e o uso de computadores, além do aprendizado em algum ambiente físico fora da escola. Ademais, o conteúdo de Matemática deveria relacionar-se a tópicos da Geometria Euclidiana.

Em seguida, uma discussão com toda a turma foi realizada a fim de determinar uma temática norteadora e que fosse capaz de contemplar o que foi sugerido pelos alunos. Com base nisso, os professores levaram como sugestão o tema "água", que foi acolhido por toda a turma. Os estudantes ficaram empolgados em visitar a Estação de Tratamento de Água (ETA) próxima à escola e em compreender o cálculo envolvido nas contas de água. Essa temática abriu diversas possibilidades de investigação, que incluíram: o estudo das características, do tratamento e distribuição da água, de questões de responsabilidade de consumo individual e sustentabilidade, além do estudo de rios do município.

Para identificar os conhecimentos prévios da turma participante acerca do tema "água" e dos assuntos de Geometria euclidiana plana, um novo questionário com perguntas abertas foi elaborado e respondido pelos alunos individualmente. A análise de suas respostas mostrou que os alunos associaram o tema principalmente à saúde, energia e higiene. Poucos sabiam que o município possui uma estação de tratamento da água e do esgoto, bem como o nome da empresa responsável por ele. Além disso, nenhum estudante afirmou saber como é realizado o cálculo das tarifas da conta de água, mas muitos demonstraram enorme interesse em aprender.

Com relação aos tópicos curriculares de Geometria, a maioria da turma não soube definir corretamente os conceitos de perímetro, área e volume, tampouco efetuar corretamente os cálculos. Ademais, muitos confundiram perímetro com área e outros reduziram este conceito a expressões do tipo: "base $\mathrm{x}$ altura", além de empregarem erroneamente as unidades de medida.

Destacamos algumas destas respostas: "área é a parte de dentro da figura" (aluno A), "área é a parte que fica dentro do perímetro" (aluno B) e "área é o espaço dentro da figura e a multiplicação dos lados da figura" (aluno C). A definição de área como sendo "a parte de dentro de uma figura" evidencia uma intuição do conceito, mas traz problemas quando se pensa em uma figura geométrica não plana, ou aberta. A imagem mental de área como multiplicação dos valores de seus lados também evidencia uma generalização errônea do conceito com o caso do retângulo, que geralmente é o primeiro a ser estudado na escola.

Aplicação das atividades: investigação exploratória e Resolução de Problemas

Diante do exposto, delineamos caminhos para a ação pedagógica no sentido de proporcionar à turma uma sequência didática capaz de ampliar os esquemas de conhecimentos prévios que os alunos possuíam e engajá-los como protagonistas na construção de seu conhecimento.

Elaboramos uma sequência de atividades dividida em dois momentos: (a) uma 
DOI: $10.20396 /$ zet.v29i00.8659781

pesquisa-exploratória do tema na sala de informática da escola e visita didática à ETA e (b) emprego da metodologia de ensino-aprendizagem-avaliação através da Resolução de Problemas na sala de aula.

No primeiro momento, os educandos realizaram uma pesquisa para conhecerem algumas questões concernentes ao tema "água" de maneira mais aprofundada, que foi realizada na internet, por meio de um levantamento bibliográfico sugerido e uma visita à ETA da empresa responsável pelo tratamento de água e esgoto do município. A partir dessas atividades, esperava-se coletar informações que fossem desencadeadoras de aprendizagem e que pudessem servir , posteriormente, de ponto de partida para o ensino-aprendizagemavaliação através da Resolução de Problemas.

Com relação à pesquisa, para que todo o processo fosse rico em termos de aprendizagem significativa para os alunos e houvesse qualidade do material encontrado, criamos um website especialmente para este momento, valendo-nos da plataforma Wix e as atividades foram realizadas no laboratório de informática da escola, que possui toda a infraestrutura necessária, com computadores suficientes e acesso à internet.

Cada grupo ficou responsável por um tema, os quais versavam sobre: i) doenças associadas à ingestão da água imprópria para consumo; ii) pesquisa sobre os principais rios do município e sua importância para a cidade; iii) descobrir como é feito o cálculo do valor da conta de água e se gastamos mais do que deveríamos; iv) onde a água que chega nas residências da cidade é tratada; v) onde o esgoto é tratado e se isso ocorria na cidade.

Foi solicitado aos alunos redigir uma síntese digitada do que foi pesquisado. A análise dos trabalhos revelou que todos os grupos responderam às perguntas norteadoras e que utilizaram o material disponibilizado, tendo compreendido a proposta da investigação. No entanto, eles apresentaram inúmeros erros gráficos e gramaticais, além de muitas dúvidas em relação à formatação do texto. Utilizaram a prática reiterada de copiar e colar trechos prontos, sendo advertidos pelo professor e pesquisador com relação a isso e ao uso de fontes que não constavam no website.

Apesar desses obstáculos, acreditamos que o trabalho, além de ter cumprido com o seu objetivo de natureza exploratória e ter permitido aprofundar os conhecimentos sobre a temática, proporcionou outras habilidades e competências interdisciplinares aos estudantes, como o desenvolvimento da escrita no computador, elaboração do texto (redação) e atividade de pesquisa, imprescindíveis para a escola do novo milênio, a qual tem como desafios preparar cidadãos que sejam capazes de se inserir em uma sociedade cada vez mais complexa, diversificada e dinâmica em suas mudanças.

Na visita à ETA da cidade, considerada aqui, à luz da teoria, como uma atividade matemático-pedagógica interdisciplinar (Rosa \& Orey, 2017), os alunos tiveram a oportunidade de conhecer os processos envolvidos no tratamento de água, além de refletirem sobre uso consciente desse recurso; ali também estiveram em contato com algumas formas geométricas espaciais, tais como paralelepípedos, cilindros e troncos de cone e puderam 
DOI: $10.20396 /$ zet.v29i00.8659781

associá-las ao trabalho desenvolvido pelos funcionários dentro da ETA.

\section{Elaboração e resolução das situações-problema}

Duas situações-problema foram elaboradas a partir do contexto da visita à ETA e versaram sobre a limpeza de tanques e distribuição de água. Consideramos principalmente os grandes tanques que possuíam formato de paralelepípedos e a partir dos quais a água, já em fase final de tratamento, é distribuída. A escolha do paralelepípedo se deu porque o tópico ainda não havia sido explorado pelo professor responsável pela turma.

A primeira situação-problema abrangeu conceitos de volume do paralelepípedo, porcentagem, área do retângulo e o emprego de grandezas e medidas relacionadas (metro, metro quadrado, metro cúbico e litro). A segunda baseou-se no conceito de proporcionalidade empregado no contexto da ETA por meio da vazão. Além disso, a situação-problema envolveu representação por frações e conversão horas-minutos-segundos.

Para a realização desta atividade, os alunos dividiram-se em quatro grupos e cada um registrou em uma folha individual as respostas construídas coletivamente. Além desses registros, o pesquisador utilizou um gravador de áudio. Salientamos, de antemão, que todas as etapas propostas por Onuchic et al. (2014), com exceção da "proposição de novos problemas", foram implementadas com êxito. A exceção ocorreu devido aos contratempos no final do período letivo, que tornaram impossível para o professor ceder as últimas aulas para discussão de futuras atividades.

Seguindo essas etapas, após as aulas em que ocorreu a resolução dos problemas propriamente dita, procedemos à socialização na lousa, quando os grupos registraram suas respostas e apresentaram os caminhos percorridos e as estratégias mobilizadas. O objetivo era facilitar os momentos posteriores, de discussão e plenária, criando um painel de resoluções para que os grupos pudessem comparar as respostas, identificar erros e chegar coletivamente à resposta correta.

Inicialmente, notou-se que alguns grupos mostraram desmotivação para ler o enunciado e dificuldades em interpretar a situação e utilizar os dados. Também ficou claro para os mediadores que poucos tinham os conhecimentos matemáticos necessários para resolver os problemas. Essas dificuldades foram sendo vencidas aos poucos, em cada grupo.

No que diz respeito às etapas da resolução dos problemas, relatamos dificuldades da turma na interpretação dos enunciados, no acesso aos conhecimentos prévios, no detalhamento das resoluções e na comunicação entre pares. Tais limitações são frequentemente relatadas em pesquisas da área sobre Resolução de Problemas, tais como Zuffi e Onuchic (2007) e Alvarenga, Andrade e Santos (2016).

Para exemplificar algumas dessas, os educandos mostraram dificuldades em compreender a situação da manutenção dos tanques descrita no problema, acessar conceitos relativos à área para desenvolver o de volume, empregar a unidade de medida correta e de associar as noções de proporção e fração. Identificamos, também, a necessidade de registros mais detalhados das ideias e dos procedimentos matemáticos adotados. Observamos, 
DOI: 10.20396/zet.v29i00.8659781

também, dificuldade na realização de cálculos com números grandes que representavam as medidas reais dos tanques da Estação. As medidas exatas e as situações expostas são elementos presentes no cotidiano dos funcionários da empresa responsável pela ETA.

Nesse sentido, a estratégia de utilizar exemplos relacionados a outros contextos, que não apenas o da situação-problema facilitou os momentos de auxílio e mediação (Bean, 2001). O diálogo a seguir, em que $P$ representa a fala do professor-pesquisador e e1, e2 e e3 representam as falas dos educandos, exemplifica uma situação na qual o uso de perguntas aproximativas foi capaz de conduzir os alunos a chegarem, por si mesmos, à resposta.

$\mathrm{e}_{1}$ : "Como a gente tinha falado naquela hora, a gente fez 32 vezes 4 , que deu 128. Aí, a gente fez vezes 12,8 . Aí, deu. 1.638,4. Aí, esse valor a gente viu que cada metro cúbico tem 1.000 litros, a gente fez esse valor vezes 1.000. Aí, deu 1.638.400,0 litros.

$\mathrm{e}_{2}$ : "E ainda vai ter mais porque vai ampliar $20 \%$. Aí, a gente vai fazer esse valor vezes 20 ".

P: "E o que vocês vão descobrir com isso? Quando faço vezes 20”?

$\mathrm{e}_{1}$ : "Nós vamos descobrir que o valor vai ficar maior".

P: "Quando vocês acharem 20\% daquilo, o valor vai ser maior"?

[Todos do grupo falaram maior também]

$\mathrm{e}_{1}$ : "Pera, quando eu achar $20 \%$ "?

P: "Vai achar um valor maior ou menor do que aquele que você tá multiplicando"?

$\mathrm{e}_{1}$ : "Maior".

$\mathrm{e}_{2}$ : "Professor, quando eu multiplicar por 20, esse 0 aqui some ou continua"?

[Apontando para o registro: 1.638.400,0]

P: "Quando eu digo 2 quilos de sabão em pó ou 2,0 quilos de sabão em pó, é a mesma coisa"?

$\mathrm{e}_{2}$ : "Mesma coisa".

$\mathrm{e}_{1}$ : "Professor, fiz 20 vezes 1.638 .400 e deu maior".

P: "Quanto deu"?

$\mathrm{e}_{1}$ : “32.768.000. Maior, viu".

P: "Concordo que é maior, mas queremos saber quanto é 20 por cento de um valor".

$\mathrm{e}_{2}$ : "Não é só multiplicar por 20 ?".

P: "Quando eu digo 100\%, estou considerando o todo. Se eu digo $20 \%$, é uma parte desse todo. Concordam?

[Todos responderam que sim].

P: "Vocês lembram-se do cálculo de porcentagem"?

$\mathrm{e}_{1}$ : "Mais ou menos".

$\mathrm{e}_{3}$ : "Tem mais"?

$\mathrm{e}_{2}$ : "Acho que precisa dividir".

P. "Se é 20 por cento, 20 dividido por 100".

$\mathrm{e}_{1}$ : "Isso. Dividindo por 100, quer ver". 
$\mathrm{e}_{1}$ : "Professor, deu um número menor"!

De modo geral, foi bastante difícil mediar o processo, pois eram muitos alunos para auxiliar e eles tinham poucos conhecimentos matemáticos prévios, como é o caso de porcentagem do exemplo anterior. Do ponto de vista do mediador, foi extremamente difícil não fornecer a resposta solicitada, principalmente para aqueles grupos que apresentavam pouco conhecimento, tendo sido necessário desvincular da situação-problema e utilizar dados mais simples, nos casos do volume, porcentagem, vazão e horas, e utilizar de perguntas aproximativas.

\section{Diagnóstico final}

Esta etapa consistiu da aplicação dos terceiro e quarto questionários aos alunos participantes, que incluíam, respectivamente, quatro questões de Matemática com os mesmos assuntos trabalhados durante a resolução de problemas, e questões sobre as contribuições para os processos de aprendizagem proporcionados pelas atividades de intervenção.

A figura a seguir ilustra dois registros, de integrantes de um mesmo grupo, durante a resolução dos problemas (à esquerda) e após, na resposta ao terceiro questionário (à direita). Neste caso, podemos notar que os registros, após todo o processo de aplicação da metodologia, foram mais detalhados, organizados e coerentes com a linguagem matemática.

Figura 1 - Respostas de dois alunos após emprego da metodologia

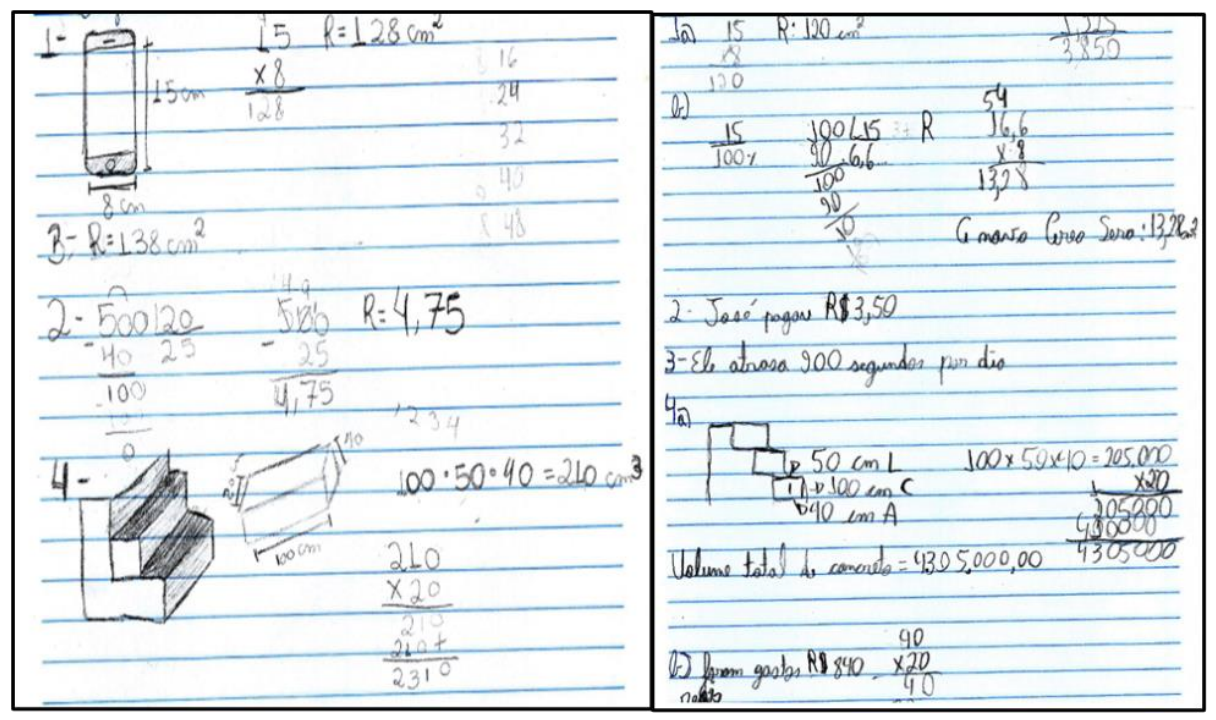

Fonte: material dos autores coletado durante a pesquisa

Com relação aos avanços na compreensão dos conceitos matemáticos, identificamos que dentre os dezesseis participantes, treze responderam corretamente à primeira questão relativa ao conceito de área e à quarta sobre volume, apresentando, também, as unidades de medida corretas. Destacamos que a turma, de modo geral, não possuía uma boa compreensão acerca das unidades de medida durante a resolução dos problemas, bem como de área. Isso revela que o conjunto das atividades, com as discussões posteriores e sínteses teóricas, 
proporcionaram aos educandos aprender esses conceitos de modo mais significativo.

Ressaltamos, no entanto, que esse avanço não foi tão expressivo com relação à proporção e porcentagem, visto que, dos dezesseis participantes, apenas quatro responderam corretamente à questão relativa a esses conceitos. Isso evidenciou, especialmente para o professor regente, a necessidade de um trabalho mais aprofundado com a turma sobre esses temas nas outras aulas em que o pesquisador não estava presente.

A última atividade realizada foi a aplicação do quarto questionário, para o qual analisaremos algumas respostas fornecidas à seguinte pergunta: "Ao longo do ano, fizemos uma visita à estação, utilizamos os computadores da escola para pesquisar, resolvemos problemas de Matemática, discutimos com toda a turma e, só depois, o professor utilizou a lousa para explicar os conceitos. $\mathrm{Na}$ sua opinião, ficou mais fácil e atraente aprender Matemática dessa maneira? Por quê?"

O total corresponde a 20 respostas, sendo que 18 (90\%) responderam "Sim" e $2(10 \%)$ responderam "Não". Com relação àqueles que responderam "Sim", houve diferenças nos argumentos, que basicamente consistiam em três grandes justificativas, referentes a: "Pesquisa", com 3 respostas (15\%), "Espaço", com 3 (15\%) e "Diferenciada", com 12 (60\%).

Os argumentos elencados como "Diferenciada" apontam que ficou mais atraente e fácil de aprender Matemática devido ao caráter dinâmico das atividades. A experiência de visitar a ETA também foi apontada como elemento motivador pelos educandos. Dentre as respostas fornecidas, destacamos: "Sim, porque nós fomos até o local para ver com o que estávamos trabalhando." (aluno A).

Outras respostas, inseridas em "Pesquisa", ressaltaram que as atividades exploratórioinvestigativas, realizadas na sala de computadores, tornaram as aulas mais atraentes e significativas, pois, através dessas, eles puderam conhecer melhor os temas. Por exemplo, "Sim, ficou mais fácil porque utilizamos computadores, lousa, e o professor explicou muito bem e bem mais atraente" (aluno B). Em igual número, identificamos respostas que enfatizaram a importância de valorizar um espaço de discussão, debates e aprendizado, no qual o educando é incentivado pelo professor e colegas a compartilhar suas dúvidas. Destacamos: "Sim, pois podemos tirar nossas dúvidas e nos sentimos mais à vontade para perguntar" (aluno C).

Com relação aos dois alunos que responderam negativamente à primeira pergunta, destacamos suas respostas: "Não, porque faltam mais aulas. Um professor passa uma coisa e o outro passa outra." (aluno D) e "Não, porque prefiro que tenha mais explicação na sala porque eu consigo entender mais.” (aluno E).

A última resposta parece estar relacionada ao fato de que os educandos não são habituados a serem protagonistas da construção de seu conhecimento e, sempre que eles têm essa oportunidade, sentem-se desconfortáveis, oferecendo resistências à proposição de atividades alternativas. A primeira, por sua vez, destaca que as atividades de pesquisa e as regulares, oferecidas pelo professor, quando frequentemente intercaladas, provocaram certa 
confusão para este aluno.

A análise das perguntas mostrou que, para a maioria dos educandos (18 dentre 20), ficou mais fácil e atraente aprender Matemática empregando a metodologia de Resolução de Problemas e utilizando os computadores da escola para pesquisar. A visita à ETA também foi elencada como fator positivo para auxiliar nas atividades e como tendo sido a primeira visita didática nessa disciplina. Além disso, as respostas mostraram que a proposta gerou um espaço para discussão e compartilhamento de ideias nas aulas de Matemática e os tópicos citados como tendo sido aprendidos foram: paralelepípedos, volumes e medidas de capacidade, áreas e perímetros, e sobre como calcular a conta de água.

Outra pergunta deste questionário indagou sobre o trabalho em grupo para a resolução dos problemas. Apesar de muitos destacarem que o diálogo e a troca de informações foram essenciais, um aluno afirmou que alguns integrantes do seu grupo não estavam interessados em resolver os problemas e que isso dificultou o trabalho com os pares. Destacamos também que, inclusive dentre aqueles que responderam positivamente à pergunta, houve ressalvas com relação à participação em grupo.

Isso evidencia que fazer com que todos os grupos e seus membros estejam engajados na atividade é também um desafio ao educador. O método de trabalho em grupo deve ser aperfeiçoado diante das circunstâncias que surgem no decorrer das aulas, principalmente com um uso mais persistente da metodologia proposta, uma vez que as ressalvas nas respostas revelam que os discursos escolares, em geral, não promovem ambientes coletivos, de compartilhamento de ideias e opiniões. Assim, os alunos não estão habituados a mudanças no contrato didático (Brousseau, 1988) das aulas de Matemática e uma proposta como esta causa diversas instabilidades com as alterações nos papéis e nas interações em sala de aula, as quais precisam de tempo e continuidade para serem absorvidas.

\section{Considerações finais}

Finalizamos este artigo respondendo às três questões de pesquisa elencadas. Salientamos que os pressupostos etnomatemáticos estiveram presentes nas atividades, na medida em que buscamos evidenciar o valor do elemento cultural da Matemática, compreendendo-a em uma perspectiva não apenas restrita aos contextos escolares, mas principalmente sociais (D’Ambrosio, 1990). Desse modo, foi possível propor e desenvolver uma ação pedagógica articulando os pressupostos da Etnomatemática e da Resolução de Problemas a partir da adoção dessas duas perspectivas simultaneamente.

Quanto à questão do que a metodologia significou em termos da aprendizagem de Matemática para os participantes, concluímos que houve avanços e que a articulação entre os conhecimentos matemáticos oriundos do contexto escolar e aqueles originados na ETA da comunidade foi de fundamental importância. Os dados evidenciaram que o caráter diferenciado e dinâmico do conjunto das atividades tornou as aulas de Matemática mais atraentes e significativas. Isto reforça o já enfatizado por D'Ambrosio (2000) e Rosa e Orey (2017), de que é necessário que os alunos tomem conhecimento da realidade na qual estão 
inseridos, compreendam a Matemática enquanto produto social e cultural.

Nossa pesquisa também corrobora o trabalho de Zuffi e Onuchic (2007), que investigaram uma experiência de prática contínua da metodologia de ensino através da Resolução de Problemas, com alunos do Ensino Médio. Destacamos que os dados permitiram apontar que as atividades aqui propostas, com a associação de duas linhas teóricometodológicas, embora se caracterizem como uma experiência inicial para os alunos, mas com uma duração razoável, totalizando treze semanas para um bom desenvolvimento das atividades, sendo cinco destas para cumprir as etapas de Resolução de Problemas no Ensino Fundamental, proporcionaram aos educandos aprender de modo mais significativo os conceitos focalizados. Os registros das resoluções de problemas pelos estudantes passaram a apresentar maiores detalhes dos procedimentos e nas operações matemáticas, bem como um melhor desempenho da sala em geral, se compararmos os questionários aplicados antes e depois da aplicação da metodologia (segundo e terceiro questionários).

Sobre a questão das dificuldades encontradas na implementação desta proposta, observamos que, nas atividades de exploração do tema, muitos alunos não conheciam o editor de texto Word, o que limitou o trabalho de escrita. Além disso, apesar de ter sido criado um website próprio com indicações bibliográficas, muitos educandos pesquisavam, em fontes não confiáveis da Internet, sem seguir esta orientação dada pelo pesquisador. Concluímos dessa atividade, que eles não tinham experiências frequentes em tarefas exploratórias e que são raramente estimulados a serem protagonistas da construção de seus conhecimentos. Apesar disso, o trabalho com essas atividades exploratório-investigativas permitiu aprofundar os conhecimentos sobre a temática e a desenvolver habilidades de escrita.

Outra problemática encontrada durante a aplicação da proposta consistiu no fato de que, apesar da maioria dos alunos pertencerem ao mesmo bairro, seus interesses e conhecimentos de Matemática eram bastante diversificados.

No tocante às condições fornecidas para a implementação desta metodologia na rede pública de ensino (pergunta 1), salientamos que fatores estruturais e organizacionais não interferiram no desenvolvimento das atividades. Inclusive, contamos com a ajuda de diversos atores da comunidade escolar, por exemplo, a Secretaria de Educação Municipal, que custeou um ônibus público para levar os alunos à Estação e a empresa responsável pelo tratamento da água, que disponibilizou, gratuitamente, uma funcionária guia. Além disso, a sala de informática da escola foi utilizada em diversos momentos e contava com todos os recursos essenciais para o bom desenvolvimento das atividades.

Por outro lado, relatamos que os principais desafios estavam relacionados à pouca familiaridade dos estudantes com propostas alternativas de ensino de Matemática, conforme apontam Correa e Maclean (1999).

No tocante à realidade da escola pública estadual paulista e considerando os calendários e diversas atividades externas que muitas vezes impedem a realização de um trabalho deste tipo, salientamos que, apesar do tempo depreendido, foi perfeitamente 
possível, desenvolver esse trabalho, e entendemos que ao longo do ano, seja muito plausível desenvolver atividades similares no Ensino Fundamental ou no Médio. Ademais, foi possível contemplar diversos tópicos importantes do currículo matemático escolar e promover situações de interdisciplinaridade.

\section{Agradecimentos:}

Os autores agradecem o apoio financeiro recebido da Fundação de Amparo à pesquisa do Estado de São Paulo - FAPESP, n. do processo: 2018/25942-2.

\section{Referências}

Alvarenga, K.B., Andrade, I.D., \& Santos, R.J. (2016). Dificuldades na resolução de problemas básicos de matemática: um estudo de caso do agreste sergipano. Amazônia: Revista de Educação em Ciências e Matemática, 12(24), 39-52.

Alves-Mazzotti, A.J. (2006). Usos e abusos dos estudos de caso. Cadernos de Pesquisa (online), 36(129), 637-51. https://doi.org/10.1590/S0100-15742006000300007

Bean, D. (2001). O que é modelagem matemática? Educação Matemática em Revista, 8(9), 49-57.

Brasil. (1998). Parâmetros Curriculares Nacionais: Matemática. Brasília: MEC/SEF.

Brasil. (2017). Base Nacional Comum Curricular: Ensino Fundamental. Brasília: MEC/SEB/CONSED/UNDIME.

Brousseau, G. (1988). Le Contrat Didactique: le milieu. Rechèrches en Didactique des Mathématiques, 9(3), 309-336.

Correa, J., \& Maclean, M. (1999). Era uma vez ... um vilão chamado Matemática: um estudo intercultural da dificuldade atribuída à Matemática. Psicologia: Reflexão e Crítica, 12(1), 173-194. https://doi.org/10.1590/S0102-79721999000100012

D’Ambrosio, U. (1990). Etnomatemática. São Paulo: Ática.

D’Ambrosio, U. (2000). Etnomatemática e Modelagem. In M.C. Domite (Ed.), Anais do Primeiro Congresso Brasileiro de Etnomatemática. (p. 142). São Paulo: FE-USP.

D’ambrosio, U. (2008). Educação numa era de transição. Revista Matemática \& Ciência, v. 1 (1), p. 8-18.

Fiorentini, D., \& Miorim, M.A. (1990). Uma reflexão sobre o uso de materiais concretos e jogos no Ensino da Matemática. Boletim da SBEM-SP, 4(7), 5-10.

Fonseca, J.J.S. (2002). Metodologia da pesquisa científica. Fortaleza: UEC.

Freire. P. (1987). Pedagogia do oprimido. $17^{\text {a }}$ ed. Rio de Janeiro: Paz e Terra.

Gonçalves, P.G.F., Bandeira, F.A., \& Araújo Júnior, G.C. (2013). Etnomatemática e resolução de problemas: do labor dos trabalhadores das indústrias de cerâmica do município de Russas-CE ao desenvolvimento de uma experiência educacional. Anais do $11^{\circ}$ Encontro Nacional de Estudantes de Matemática, Curitiba: Sociedade Brasileira de Educação Matemática (SBEM). 
DOI: $10.20396 /$ zet.v29i00.8659781

Mandarino, M.C.F. (2002). Os professores e a arte de formular problemas contextualizados. Anais da $2^{a}$ Bienal da Sociedade Brasileira de Matemática. Salvador: Sociedade Brasileira de Matemática. Retirado em 20 de maio, 2020, de: http://www.bienasbm.ufba.br/OF12.pdf.

Monteiro, A. (2004). Algumas reflexões sobre a perspectiva educacional da Etnomatemática. Zetetiké, 12(2), 9-32.

Onuchic, L.R. (1999). Ensino-aprendizagem de Matemática através da Resolução de Problemas. In M.A.V. Bicudo (Org.), Pesquisa em educação matemática: concepções e perspectivas. (pp. 199-218). São Paulo: Editora UNESP.

Onuchic, L.R., \& Allevato, N.S.G. (2005). Novas reflexões sobre o ensino-aprendizagem de Matemática através da Resolução de Problemas. In M.A.V. Bicudo \& M.C. Borba (Orgs.), Educação Matemática: pesquisa em movimento. (pp. 213-231). São Paulo: Cortez.

Onuchic, L.R., \& Allevato, N.S.G. (2011). O Estado da Arte da Resolução de Problemas. In Anais do $5^{\circ}$ Congresso Internacional de Ensino de Matemática (pp. 1-12). Canoas: ULBRA.

Onuchic, L.R., Allevato, N.S.G., Noguti, F.C.H., \& Justulin, A.M. (Orgs.) (2014). Resolução de Problemas: Teoria e prática. Jundiaí: Paco.

Pereira, M.I.C., \& Bandeira, F.A. (2016). Etnomatemática e Resolução de Problemas como ferramentas de intervenção no ensino e aprendizagem da Matemática na Educação de Jovens e Adultos - EJA. In Anais do $9^{\circ}$ Encontro Paraibano de Educação Matemática (EPPBEM). Campina Grande: Sociedade Brasileira de Educação Matemática-PB.

Pires, C.M.C. (2008). Educação matemática e sua influência no processo de organização e desenvolvimento curricular no Brasil. Boletim de Educação Matemática (Bolema), 21 (29), 13-42.

Polya, G. (1978). A arte de resolver problemas. Rio de Janeiro: Interciências.

Rosa, M., \& Orey, D. C. Influências etnomatemáticas em salas de aula: caminhando para a ação pedagógica. Curitiba: Appris.

Rosa, M., D’Ambrosio, U., Orey, D.C., Shirley, L., Alangui, W.V., Palhares, P., \& Gavarreta, M.E. (2016). Current and future perspectives of ethnomathematics as a program. Hamburg: Springer. https://doi.org/10.1007/978-3-319-30120-4

Teixeira, L. R. M. (2004). Dificuldades e erros na Aprendizagem da Matemática. In Anais do $7^{\circ}$ Encontro Paulista de Educação Matemática (EPEM). São Paulo: Sociedade Brasileira de Educação Matemática (SBEM).

Thiollent, M. (2000). Metodologia da pesquisa-ação. São Paulo: Cortez.

Zuffi, E.M., \& Onuchic, L.R. (2007). O Ensino-Aprendizagem de Matemática através da Resolução de Problemas e os Processos Cognitivos Superiores. Revista Ibero americana de Educación Matemática (Unión), 11, 79-97.

Wanderer, F., \& Knijnik, G. (2008). Discursos produzidos por colonos do sul do país sobre a matemática e a escola de seu tempo. Revista Brasileira de Educação, 13(39), 555-564. 